\title{
KINERJA PEGAWAI NEGERI SIPIL DI KECAMATAN BOGOR SELATAN KOTA BOGOR
}

\section{CIVIL SERVANT PERFORMANCE IN BOGOR SELATAN DISTRICT BOGOR CITY}

\author{
Jun Sam Yang1*, Denny Hernawan², G. Goris Seran³ \\ 1,2,3Program Studi Administrasi Publik, Fakultas Ilmu Sosial dan Ilmu Politik, Universitas \\ Djuanda, Jl. Tol Ciawi No. 1, Kotak Pos 35, Bogor 16720
}

*Korespondensi: Jun Sam Yang. Email: vzr106@naver.com

(Diterima: 23-01-2020; Ditelaah: 04-02-2020; Disetujui: 25-02-2020)

\begin{abstract}
The purpose of this research is to describe the performance of civil servants in Bogor Selatan District Bogor City. According to Robbins, there are five dimensions to measure the performance of civil servants, namely, quality, quantity, pomptnees, effectiveness, and independence. Method of this research is descriptive qualitative. Population of this research consists of 24 civil servants in Bogor Selatan District Bogor City and all civil servants are made as the research sample. Data of this research are collected by the field research (questionnaires, interviews and observations) to find out primary data and by the library research to find out secondary data. Data of the questionnaires are analyzed by using the Weight Mean Score formula to calculate the mean score. Secondary data are used to enrich the discussion of the performance of civil servants. Results of this research indicate that the performance of civil servants gets the mean score 3.6 perceived as good. This means that most of the performance of civil servants in Bogor Selatan District Bogor City are already good as they carry out their main duties and functions in supporting to achieve the realization of vision, mission, aims and goals of Bogor Selatan District Bogor City. Such good condition can be proved from the rewards appreciated by the head of district, the progress of job quality of civil servants, the improvement of job management knowledge, the job completion suitable to the determined target, and the inisiative of civil servants to implement the job not merely depending on the head of district.
\end{abstract}

Key words: Bogor City, Civil Servant, Performance, Local Government.

\begin{abstract}
ABSTRAK
Tujuan penelitian ini adalah untuk menggambarkan kinerja pegawai negeri sipil di Kecamatan Bogor Selatan Kota Bogor. Robbins mengemukakan lima dimensi untuk mengukur kinerja pegawai negeri sipil, yaitu kualitas (quality), kuantitas (quantity), ketepatan waktu (pomptnees), efektivitas (effectiveness), dan kemandirian (independence). Metode penelitian deskriptif kualitatif. Populasi penelitian ini terdiri dari seluruh pegawai negeri sipil Kecamatan Bogor Selatan sebanyak 24 orang dan semuanya dijadikan sebagai sampel penelitian. Data penelitian dikumpulkan dengan penelitian lapangan (kuesioner, wawancara dan pengamatan) untuk mendapatkan data primer dan penelitian kepustakaan untuk mengumpulkan data sekunder. Data kuesioner dianalisis dengan menggunakan rumus Weight Mean Score untuk menghitung skor rerata. Data sekunder digunakan untuk memperkaya pembahasan tentang kinerja pegawai negeri sipil. Hasil penelitian menunjukkan bahwa kinerja pegawai negeri sipil memperoleh skor rerata sebesar 3,6 yang dikategorikan baik. Ini berarti bahwa rata-rata kinerja pegawai di Kecamatan Bogor Selatan sudah baik dalam melaksanakan tugas dan fungsi sehingga dapat membantu pencapaian visi, misi, tujuan dan sasaran Kecamatan Bogor Selatan Kota Bogor. Kondisi baik tersebut dapat dilihat dari adanya penghargaan yang diberikan oleh atasan/camat, kemajuan kualitas pekerjaan pegawai, peningkatan pengetahuan dalam aktivitas pengelolaan pekerjaan, penyelesaian pekerjaan sesuai dengan target yang telah ditetapkan, dan inisiatif pegawai dalam melaksanakan pekerjaan tidak semata-mata bergantung pada atasan/camat.
\end{abstract}

Kata kunci: Kota Bogor, Pegawai Negeri Sipil, Kinerja, Pemerintahan Daerah.

Yang, Jun Sam, Hernawan, Denny \& Seran, G. Goris. (2020). Kinerja Pegawai Negeri Sipil di Kecamatan Bogor Selatan Kota Bogor. Jurnal GOVERNANSI, 6(1): 57-62. 


\section{PENDAHULUAN}

Kinerja organisasi dewasa ini telah menjadi sorotan publik, karena adanya iklim keterbukaan dan demokratisasi. Selain itu, untuk mengukur keberhasilan organisasi dalam menjalankan tugas pokok dan fungsi sulit dilakukan secara obyektif. Kesulitan tersebut timbul karena belum tersusunnya sistem pengukuran kinerja yang menginformasikan tingkat keberhasilan organisasi. Dalam melaksanakan pekerjaan atau tugas-tugas yang menjadi tanggung jawab seorang pegawai, maka yang menjadi tolok ukurnya adalah kinerja.

Kinerja merupakan fungsi kecakapan atau kepandaian dan motivasi. Dengan demikian, kinerja merupakan unjuk kerja yang dapat dicapai oleh pegawai dalam melaksanakan tugas-tugas pekerjaannya sesuai dengan kewenangan dan tanggung jawabnya dalam upaya mencapai tujuan organisasi. Hal ini dapat ditunjukkan dengan indikator-indikator seperti menyelesaikan tugas dengan baik dan benar, mentaati prosedur dan aturan kerja, memiliki inisiatif dalam bekerja, menjaga kualitas kerja, berperilaku baik dan tanggap terhadap tuntutan kerja, serta mencapai tujuan yang telah ditetapkan sesuai agenda kerja. Kinerja pegawai dan kinerja organisasi mempunyai keterkaitan yang erat. Tercapainya tujuan organisasi tidak dapat dilepaskan sumber daya yang dimiliki oleh organisasi yang digunakan atau dijalankan oleh pegawai yang berperan aktif sebagai pelaku dalam upaya mencapai tujuan organisasi tersebut.

Kecamatan Bogor Selatan Kota Bogor menjadi lokus penelitian tentang kinerja pegawai negeri sipil. Dalam hal ini, kecamatan merupakan bagian wilayah dari daerah kabupaten/kota yang dipimpin oleh camat (Undang-Undang Nomor 23 Tahun 2014 tentang Pemerintahan Daerah, Pasal 1 angka 24). Sebagai perangkat daerah, Camat Bogor Selatan mendapatkan pelimpahan wewenang dalam hal pelayanan kepada masyarakat dari Wali Kota Bogor. Selain itu, Kecamatan Bogor Selatan juga bertugas dalam penyelenggaraan tugas-tugas umum bidang pemerintahan.

Berdasarkan hasil pengamatan peneliti di Kecamatan Bogor Selatan Kota Bogor, kinerja pegawai negeri sipil masih belum optimal. Hal ini mungkin disebabkan oleh beberapa hal sebagai berikut: (1) Kurang efektif yaitu kurangnya pegawai yang memiliki pengetahuan atau kemampuan baik secara kualitas maupun kuantitas di bidangnya dimana kualitas organisasi sangat tergantung dari sejauhmana sumber daya manusia atau pegawainya dapat menyelesaikan tugas dan kegiatannya seefektif mungkin. Pegawai diharapkan dapat menyelesaikan 2 sampai 3 pekerjaan dalam 1 hari, ternyata masih banyak yang menyelesaikan tugas tidak sesuai dengan target. (2) Masih adanya keluhan masyarakat atas pelayanan yang diberikan. (3) Dalam upaya memberi motivasi kepada pegawai, perlu adanya komunikasi antara pimpinan dan pegawainya agar tercipta lingkungan pekerjaan yang harmonis. (4) Pemimpin dalam mengambil keputusan terkadang tidak melibatkan bawahan, karena keputusan harus diambil secara cepat. Beberapa hal tersebut dapat mempengaruhi peningkatan kinerja pegawai di Kecamatan Bogor Selatan Kota Bogor.

Dengan demikian, berdasarkan latar belakang tersebut, penelitian ini bertujuan untuk menggambarkan tentang kinerja pegawai negeri sipil di Kecamatan Bogor Selatan Kota Bogor.

\section{MATERI DAN METODE} Konsep/Teori yang Relevan

Berkaitan dengan kinerja pegawai, kinerja tanpa sumber daya manusia tidak akan dicapai hasil kerja yang diharapkan suatu organisasi. Untuk memudahkan pengkajian kinerja pegawai, kinerja merupakan kemampuan seseorang dalam melaksanakan tugas yang diberikan oleh organisasi.

Mangkunegara (2014) mengatakan bahwa kinerja adalah hasil kerja secara kualitas dan kuantitas yang dicapai oleh 
seseorang pegawai dalam melaksanakan tugasnya sesuai dengan tanggung jawab yang diberikan kepadanya. Hasibuan (2005) mendefinisikan kinerja (prestasi kerja) adalah suatu hasil kerja yang dicapai seseorang dalam melaksanakan tugas-tugas yang dibebankan kepadanya yang didasarkan atas kecakapan, pengalaman dan kesungguhan serta waktu.

Untuk mengukur kemampuan kinerja pegawai maka dilakukan penilaian atas nilai seorang individu pegawai bagi organisasinya, dilakukan oleh atasan atau seseorang yang berada dalam posisi untuk mengamati/menilai kinerja. Penilaian ini dilakukan secara sistematis mengenai kinerja pegawai dalam pekerjaannya dan posisinya untuk pengembangan. Penilaian dimaksudkan untuk mengukur kontribusi pegawai kepada organisasi tempat bekerja. Penilaian merupakan gambaran sistematis tentang kekuatan dan kelemahan yang terkait dengan pekerjaan dari seseorang atau satu kelompok.

Hasil penelitian Mote, Rahmawati, dan Seran (2019) menunjukkan kinerja pegawai dinilai rata-rata baik. Pegawai senantiasa mendapatkan penghargaan yang diberikan oleh atasan, kemajuan kualitas pekerjaan pegawai, peningkatan pengetahuan dalam aktivitas pengelola pekerjaan, penyelesaian pekerjaan sesuai dengan target yang telah ditetapkan, inisiatif setiap pegawai dalam melakukan pekerjaan tidak tergantung pada pimpinan. Hal ini didukung oleh managerial skill camat untuk meningkatkan kinerja pegawai dalam melaksanakan programprogram yang ditetapkan organisasi.

Robbins (2006) mengemukakan lima dimensi untuk mengukur kinerja pegawai, yaitu: (1) kualitas (quality), (2) kuantitas (quantity), (3) ketepatan waktu (pomptnees), (4) efektivitas (effectiveness), dan (5) kemandirian (independence). Kelima dimensi kinerja pegawai tersebut diuraikan oleh Robbins (2006) sebagai berikut:

Pertama: Kualitas (Quality). Kualitas (quality) diukur berdasarkan persepsi pegawai terhadap pekerjaan yang dihasilkan serta ketrampilan dan kemampuan pegawai. Kualitas kerja dicapai berdasarkan syarat-syarat kesesuaian dan kesiapan yang tinggi sehingga pada gilirannya dapat melahirkan penghargaan dan kemajuan serta perkembangan organisasi melalui peningkatan pengetahuan dan ketrampilan secara sistematis.

Kedua: Kuantitas (Quantity). Kuantitas (quantity) diukur berdasarkan jumlah suatu pekerjaan yang dilakukan oleh seorang pegawai dalam periode tertentu. Hal ini dapat dilihat dari hasil kerja pegawai dalam penggunaan waktu tertentu dan kecepatan dalam menyelesaikan tugas dan tanggung jawabnya.

Ketiga: Ketepatan Waktu (Pomptnees). Ketepatan waktu (pomptnees) diukur berdasarkan pekerjaan yang dapat diselesaikan atau suatu hasil produksi yang dapat dicapai, pada permulaan waktu yang ditetapkan, dilihat dari sudut koordinasi dengan hasil output serta memaksimalkan waktu yang tersedia untuk aktivitas lain.

Keempat: Efektivitas (Effectiveness). Efektivitas (effectiveness) diukur berdasarkan usaha untuk memaksimalkan tingkat penggunaan sumber daya organisasi (tenaga, uang, teknologi, bahan baku) dengan tujuan untuk meningkatkan hasil setiap unit dalam penggunaan sumber daya yang ada.

Kelima: Kemandirian (Independence). Kemandirian (independence) diukur berdasarkan tingkat seorang pegawai yang nantinya dapat menjalankan fungsi kerjanya.

\section{Metode}

Metode yang digunakan dalam penelitian ini adalah metode deskriptif. Sugiyono (2014) mengemukakan metode penelitian deskriptif sebagai metode yang dipergunakan untuk mengetahui nilai variabel penelitian secara mandiri. Dalam konteks demikian, penelitian ini bertujuan 
untuk menggambarkan kinerja pegawai negeri sipil di Kecamatan Bogor Selatan Kota Bogor.

Dalam penelitian ini, populasi adalah wilayah generalisasi yang terdiri atas subyek atau objek mempunyai kualitas dan karakteristik tertentu yang telah ditetapkan oleh peneliti dan untuk mempelajari dan kemudian ditarik kesimpulan (Sugiyono, 2014). Populasi dalam penelitian ini adalah seluruh pegawai di Kecamatan Bogor Selatan Kota Bogor sebanyak 24 orang. Menurut Sugiyono (2014), sampling jenuh adalah teknik penentuan sampel bila anggota populasi seluruhnya digunakan sebagai sampel. Dengan demikian, semua pegawai di Kecamatan Bogor Selatan Kota Bogor yang berjumlah 24 orang seluruhnya dijadikan sebagai sampel penelitian.

Penelitian ini membutuhkan data primer dan data sekunder. Pengumpulan data penelitian tersebut ditempuh dengan dua teknik, yaitu:

Pertama: Penelitian Lapangan (Field Research). Penelitian lapangan (field research) dilakukan untuk mengumpulkan data primer melalui tiga cara, yakni:

1) Kuesioner (Questionaire). Kuesioner yang diberikan kepada responden bersifat tertutup dimana pilihan-pilihan jawaban sudah disediakan dan responden tinggal memilih salah satu di antara jawaban-jawaban yang tersedia. Kuesioner berisi pertanyaan-pertanyaan tentang dimensi-dimensi kinerja pegawai di Kecamatan Bogor Selatan Kota Bogor. Kuesioner disusun secara ordinal dengan menggunakan skala Likert dengan lima pilihan jawaban, yaitu sangat baik, baik, cukup baik, tidak baik, dan sangat tidak baik.

2) Wawancara (Interview). Wawancara dilakukan kepada pegawai negeri sipil di Kecamatan Bogor Selatan Kota Bogor. Wawancara dilakukan dengan menggunakan pertanyaan-pertanyaan yang bersifat terbuka untuk mengetahui gambaran tentang kinerja pegawai.
3) Pengamatan (Observation). Pengamatan dilakukan untuk mengumpulkan data primer yang berhubungan dengan kinerja pegawai dengan mengamati perilaku kerja pegawai negeri sipil di Kecamatan Bogor Selatan Kota Bogor.

Kedua: Penelitian Kepustakaan (Library Research). Penelitian kepustakaan (library research) dilakukan untuk mengumpulkan data sekunder dari laporan/dokumen, pustaka (buku dan jurnal) dan peraturan perundang-undangan yang berkenaan dengan kinerja pegawai khususnya di Kecamatan Bogor Selatan Kota Bogor.

Pengolahan dan analisis data penelitian dilakukan secara kualitatif. Dengan mengacu pada pendapat Labovits, et al. (1982), pembahasan data penelitian dibantu dengan perhitungan skor rerata melalui rumus Weight Mean Score/WMS (Siregar, 1982). Skor rerata tersebut dihasilkan dari hasil perhitungan terhadap setiap jawaban, dimana setiap jawaban responden diberi skor berdasarkan lima gradasi dalam skala Likert, yaitu: (a) sangat baik diberi skor 5, (b) baik diberi skor 4, (c) cukup baik diberi skor 3, (d) tidak baik diberi skor 2, dan (e) sangat tidak baik diberi skor 1. Berdasarkan skor rerata tersebut, kemudian dilakukan interpretasi kategori penilaian terhadap kinerja pegawai (Tabel 1).

Tabel 1. Penafsiran Hasil Jawaban Responden

\begin{tabular}{ll}
\hline Skala Interval & Kategori Penilaian \\
\hline $4,21-5,00$ & Sangat Baik \\
\hline $3,41-4,20$ & Baik \\
\hline $2,61-3,40$ & Cukup Baik \\
\hline $1,81-2,60$ & Tidak Baik \\
\hline $1,00-1,80$ & Sangat Tidak Baik \\
\hline
\end{tabular}

Sumber: Sugiyono, 2014

\section{HASIL DAN PEMBAHASAN}

Kecamatan Bogor Selatan merupakan salah satu kecamatan di Kota Bogor, yang membawahi 16 kelurahan. Secara geografis, wilayah Kecamatan Bogor Selatan seluas 3081 Ha. Jumlah penduduk Kecamatan Bogor Selatan sebanyak 177.529 jiwa. 
Peraturan Daerah Kota Bogor Nomor 7 Tahun 2016 tentang Pembentukan dan Susunan Perangkat Daerah Kota Bogor menyatakan bahwa kecamatan mempunyai tugas pokok melaksanakan sebagian urusan di bidang pemerintahan. Dalam melaksanakan sebagian urusan sebagaimana tertera pada tugas dan fungsinya, Kecamatan Bogor Selatan Kota Bogor didukung oleh ketersediaan pegawai negeri sipil sebanyak 24 orang (Tabel 2).

Tabel 2. Jumlah dan Persentase Pegawai Kecamatan Bogor Selatan Kota Bogor Berdasarkan Golongan

\begin{tabular}{lcc}
\hline Golongan & $\begin{array}{c}\text { Jumlah } \\
\text { Pegawai }\end{array}$ & $\begin{array}{c}\text { Persentase } \\
(\%)\end{array}$ \\
\hline Pembina IV/a & 2 & 8 \\
\hline Penata Tk I-III/d & 5 & 21 \\
\hline Penata III/c & 3 & 13 \\
\hline Penata Muda Tk I-III/b & 1 & 4 \\
\hline Penata Muda Tk I-III/a & 5 & 21 \\
\hline Pengatur Tk I-II/d & 2 & 8 \\
\hline Pengatur II/c & 5 & 21 \\
\hline Pengatur Muda II/a & 1 & 4 \\
\hline Jumlah & 24 & 100 \\
\hline
\end{tabular}

Sumber: Data diolah, 2019

Tabel 2 menunjukkan sebaran pegawai Kecamatan Bogor Selatan Kota Bogor bahwa dari jumlah 24 orang terdapat lebih banyak pegawai dengan golongan Penata Tk I-III/d, Penata Muda Tk I-III/a, dan Pengatur II/c sebanyak 15 orang (60\%).

Hasil penelitian tentang kinerja pegawai negeri sipil di Kecamatan Bogor Selatan Kota Bogor dapat dideskripsikan berdasarkan dimensi kualitas, kuantitas, ketepatan waktu, efektivitas, dan kemandirian. Rekapitulasi jawaban responden tentang kinerja pegawai negeri sipil di Kecamatan Bogor Selatan Kota Bogor ditunjukkan pada Tabel 3.

Tabel 3. Rekapitulasi Jawaban Responden tentang Kinerja Pegawai Negeri Sipil di Kecamatan Bogor Selatan Kota Bogor

\begin{tabular}{llcc}
\hline No. & Indikator & Rerata & Kategori \\
\hline 1 & Kualitas & 3,9 & Baik \\
\hline 2 & Kuantitas & 3,8 & Baik \\
\hline 3 & Ketepatan Waktu & 4,0 & Baik \\
\hline 4 & Efektivitas & 3,5 & Baik \\
\hline 5 & Kemandirian & 3,2 & Cukup Baik \\
\hline & Jumlah & 3,6 & Baik \\
\hline
\end{tabular}

Sumber: Data diolah, 2019
Pada Tabel 3, kinerja pegawai negeri sipil di Kecamatan Bogor Selatan Kota Bogor secara keseluruhan menunjukkan skor rerata sebesar 3,6 yang artinya berada pada kategori penilaian baik. Berdasarkan wawancara dengan Camat Bogor Selatan, pegawai negeri sipil sudah bekerja dengan baik dan maksimal. Kondisi baik tersebut dapat dilihat dari adanya penghargaan yang diberikan oleh atasan/camat, kemajuan kualitas pekerjaan pegawai, peningkatan pengetahuan dalam aktivitas pengelolaan pekerjaan, penyelesaian pekerjaan sesuai dengan target yang telah ditetapkan, dan inisiatif pegawai dalam melaksanakan pekerjaan tidak semata-mata bergantung pada atasan/camat.

Camat Bogor Selatan Kota Bogor lebih lanjut mengemukakan bahwa beberapa hambatan yang mempengaruhi kinerja pegawai dapat diatasi melalui ditempuhnya pendidikan dan pelatihan, adanya penyampaian pendapat pegawai kepada atasan/ camat, adanya penyampaian keluhan yang pegawai alami dalam proses pekerjaan saat atasan/camat melakukan evaluasi, adanya komunikasi antar pegawai antara rekan yang satu dan rekan kerja yang lain di dalam organisasi, dalam hal ini di Kecamatan Bogor Selatan Kota Bogor. Hal-hal demikian dilakukan oleh pegawai dalam rangka mendukung kemajuan pelaksanaan tugas dan fungsi Kecamatan Bogor Selatan Kota Bogor.

\section{KESIMPULAN DAN REKOMENDASI}

\section{Kesimpulan}

Berdasarkan hasil penelitian yang telah dibahas di atas, maka dapat ditarik kesimpulan sebagai berikut:

1) Kinerja pegawai negeri sipil Kecamatan Bogor Selatan memperoleh skor rerata sebesar 3,6 yang artinya berada pada kategori baik. Hal ini menjelaskan bahwa pegawai negeri sipil di Kecamatan Bogor Selatan secara umum sudah bekerja dengan baik dinilai berdasarkan dimensi kualitas, kuan- 
titas, ketepatan waktu, efektivitas, dan kemandirian.

2) Kondisi kinerja pegawai yang baik tersebut tercipta karena adanya penghargaan yang diberikan oleh atasan/ camat, kemajuan kualitas pekerjaan pegawai, peningkatan pengetahuan dalam aktivitas pengelolaan pekerjaan, penyelesaian pekerjaan sesuai dengan target yang telah ditetapkan, dan inisiatif pegawai dalam melaksanakan pekerjaan tidak semata-mata bergantung pada atasan/camat.

\section{Rekomendasi}

Penelitian ini merekomendasikan halhal sebagai berikut:

1) Setiap indikator kinerja pegawai negeri sipil dari hasil penelitian menunjukkan kriteria yang baik pula, tetapi sebaiknya perlu adanya pengawasan yang ketat serta evaluasi pegawai dalam melaksanakan tugas atau pekerjaannya. Hal ini diperlukan untuk mendorong tanggung jawab pegawai terhadap pekerjaan yang dibebankan kepadanya.

2) Pegawai negeri sipil Kecamatan Bogor Selatan hendaknya memperhatikan ketelitian dalam melaksanakan pekerjaannya dan berperan aktif dalam lingkungan pekerjaan serta memanfaatkan fasilitas yang diberikan di tempat kerja.

\section{DAFTAR PUSTAKA}

\section{Buku}

Hasibuan, Malayu S. P. (2005). Manajemen Sumber Daya Manusia. Edisi Revisi. Jakarta: Bumi Aksara.

Labovits, Sanford, et al. (1982). Metode Riset Sosial: Suatu Pengantar. Terjemahan Bakrie Siregar. Jakarta: Erlangga.

Mangkunegara, A. A. Anwar Prabu. (2014). Evaluasi Kinerja SDM. Cetakan Keenam. Bandung: Penerbit Refika Aditama.
Robbins, Stephen P. (2006). Perilaku Organisasi. Jakarta: PT Indeks, Kelompok Gramedia.

Sugiyono. (2014). Metode Penelitian Kuantitatif Kualitatif dan $R \& D$. Bandung: Alfabeta.

\section{Jurnal}

Mote, Yohanes; Rahmawati, Rita \& Seran, G. Goris. (2019). "Managerial Skill Camat Untuk Meningkatkan Kinerja Pegawai Di Kecamatan Ciawi Kabupaten Bogor". Jurnal GOVERNANSI, 5(2): 123-130.

\section{Peraturan Perundang-undangan}

Peraturan Daerah Kota Bogor Nomor 7 Tahun 2016 tentang Pembentukan dan Susunan Perangkat Daerah Kota Bogor (Lembaran Daerah Kota Bogor Tahun 2016 Nomor 1 Seri D).

Undang-Undang Nomor 23 Tahun 2014 tentang Pemerintahan Daerah (Lembaran Negara Republik Indonesia Tahun 2014 Nomor 244, Tambahan Lembaran Negara Republik Indonesia Nomor 5587). 